\title{
SIMULTANEOUS KINETIC ANALYSIS OF RESTING AND PROLIFERATIVE B AND T LYMPHOCYTES FOLLOWING PATHOGENIC CHALLENGE IN RAINBOW TROUT (ONCORHYNCHUS MYKISS)
}

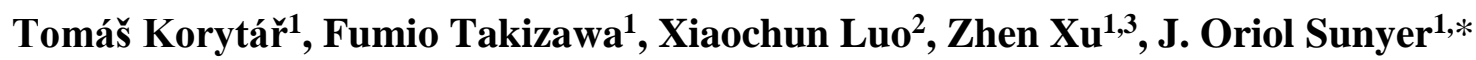 \\ ${ }^{1}$ Department of Pathobiology, School of Veterinary Medicine, University of Pennsylvania, \\ Philadelphia, Pennsylvania, USA \\ ${ }^{2}$ School of Bioscience and Bioengineering, South China University of Technology, Guangzhou \\ 510006, China \\ ${ }^{3}$ Department of Aquatic Animal Medicine, College of Fisheries, Huazhong Agricultural \\ University, Wuhan, Hubei, 430070, China
}

\begin{abstract}
Very little is known with regards to the mechanisms involved in the induction of adaptive B- and Tcell responses in teleost systemic and mucosal lymphoid organs. This knowledge in fish species has been held back for decades due to the absence of reliable monoclonal antibodies recognizing different fish leukocytes subpopulations. In the past we have produced mAbs to rainbow trout $\operatorname{IgT}$ and, more recently to rainbow trout $C D 4$, which have enabled the characterization of $\operatorname{IgT}^{+} \mathrm{B}$ cell and $\mathrm{CD} 4^{+} \mathrm{T}$ cell subsets respectively. The potential of these antibodies is shown here by a newly developed multicolor flow cytometry strategy that allows the concomitant detection of $\operatorname{IgT}^{+} \mathrm{B}$ cells, $\operatorname{IgM}^{+} \mathrm{B}$ cells, CD4$1^{+} / \mathrm{CD} 4-2^{+} \mathrm{T}$ cells, CD4-2+ $\mathrm{T}$ cells and $\mathrm{CD} 4^{+}$monocytes/macrophages in both systemic and mucosal lymphoid organs. This multicolor assay was thereafter used as a fast and efficient method to analyze the kinetics of resting and proliferative B and T cells over a two week period, upon challenge of fish with a sublethal dose of Yersinia ruckeri. Overall, our results identified the spleen as the major site for $\mathrm{CD}^{+} \mathrm{T}$ cell proliferation with significant proliferative responses occurring already 3 days post infection. Lower $\mathrm{CD} 4^{+} \mathrm{T}$ cell proliferative responses were detected in head kidney, gill and gut. The $\mathrm{B}$ lymphocytes (IgT and $\operatorname{IgM}$ ) proliferated in spleen, head kidney and gills, thus pointing to the gills as a main inductor site in mucosal responses to $Y$. ruckeri. To further explore the initial stages of lymphocyte mobilization and how this correlates with the development of adaptive immune responses in mucosal lymphoid tissues, we have applied this powerful approach to analyzing B and $\mathrm{T}$ cell response kinetics to Ichthyophthirius multifiliis, a parasite with a tropism for the skin and gills of trout. Additionally, to gain deeper insights into the spatial organization and interaction of B/T lymphocytes within the systemic and mucosal lymphoid organs, we have complemented the flow cytometry analyses with multicolor fluorescence microscopy imaging. This combined approach offers unprecedented opportunities for understanding the geography and the mechanisms by which adaptive immune responses in systemic and mucosal lymphoid organs are induced in teleost fish. In turn, such analysis will not only shed light into the pathways used by teleosts to develop adaptive immune responses, but will also provide the knowledge to rationally design better fish vaccines.
\end{abstract}

\section{KEYWORDS}

Multicolor flow cytometry, B lymphocytes, T cells, Microscopy, Cell trafficking

*Corresponding author. TEL.: 215-573-8592; Fax number: 215-898-7887

E-mail: sunyer@vet.upenn.edu 